\title{
Psychosocial Lived Experience of Parents with Children Diagnosed with Cancer in Lubumbashi
}

\author{
Criss Koba Mjumbe ${ }^{1,2^{*}}$, Béatrice Koba Bora ${ }^{3}$, Oscar Luboya Numbi ${ }^{1,2,4}$, \\ Prosper Kalenga Mwenze1,2,5, Henry Mundogo Tshamba1,2, Benjamin Kabyla Ilunga1,2, \\ Jean Pierre Birangui 6
}

${ }^{1}$ Department of Public Health, Faculty of Medicine, University of Lubumbashi, Lubumbashi, Democratic Republic of Congo ${ }^{2}$ School of Public Health, University of Lubumbashi, Lubumbashi, Democratic Republic of Congo

${ }^{3}$ Department of Neuropsychiatry, Faculty of Medicine, University of Lubumbashi, Lubumbashi, Democratic Republic of Congo ${ }^{4}$ Pediatric Oncology Unit, Lubumbashi University Clinic, Faculty of Medicine, University of Lubumbashi, Lubumbashi,

Democratic Republic of Congo

${ }^{5}$ Department of Obstetrics and Gynecology, Faculty of Medicine, University of Lubumbashi, Lubumbashi,

Democratic Republic of Congo

${ }^{6}$ Department of Clinical Psychology, Faculty of Educational Sciences, University of Lubumbashi, Lubumbashi,

Democratic Republic of Congo

Email: ${ }^{\star}$ koba.mjumbe@unilu.ac.cd

How to cite this paper: Mjumbe, C.K., Bora, B.K., Numbi, O.L., Mwenze, P.K., Tshamba, H.M., Ilunga, B.K. and Birangui, J.P. (2020) Psychosocial Lived Experience of Parents with Children Diagnosed with Cancer in Lubumbashi. Journal of Cancer Therapy, 11, 749-757.

https://doi.org/10.4236/jct.2020.1112065

Received: September 1, 2020

Accepted: November 30, 2020

Published: December 3, 2020

Copyright $\odot 2020$ by author(s) and Scientific Research Publishing Inc. This work is licensed under the Creative Commons Attribution International License (CC BY 4.0).

http://creativecommons.org/licenses/by/4.0/

(c) (i) Open Access

\begin{abstract}
Objective: To determine the psychosocial problems, social acceptance and the impact of the costs of parents whose child has cancer. Method: We carried out a descriptive cross-sectional study over two-year periods (from January 3, 2018 to March 31, 2020) in the pediatric oncology unit of clinics at the University of Lubumbashi, in DR Congo. Results: 129 parents of children with cancer in the pediatric oncology unit were included in our study. Most children with cancer (53\%) were accompanied by their mothers who had a low level of education (53.0\%). Emotional shock was the most observed reaction (68\%) to the announcement of the disease (cancer). Retinoblastoma has had a significant economic impact on families without medical coverage. Only $38 \%$ received psychological support from parents. Sadness was the most common feeling (77\%) of households. Support workers consider their relationship with the medical profession acceptable in $67 \%$ and difficult in $11 \%$. The majority of parents (78\%) felt that the time to provide medical care was longer than expected. Conclusion: Parents of children with cancer had different feelings and reactions. This observation may be useful for the development of a health policy, in particular that of pediatric cancer in DR Congo.
\end{abstract}




\section{Keywords}

Cancer, Psychological Aspect, Social Aspect, Parents, Treatment

\section{Introduction}

In general a diagnosis of childhood cancer can significantly affect the psychological well-being of patient and his family, in turn, it may also have an impact on treatment tolerance and outcomes. Nevertheless, Cancer remains a chronic condition and its medical care is always longer, increases the costs of health care and affects the psychological state of patient and his entourage. Cancer worldwide is a serious public health problem that incidence is characterized by great geographic variability [1] [2]. Various studies conducted in recent decades have revealed that the levels of pathological distress are very prevalent in oncology: the figures range from $5 \%$ to $50 \%$, depending on the characteristics and methods of treatment of the disease, but also evaluation procedures [3]. Health care providers often fail to recognize the psychological distress of cancer patients or the family environment [4]. As a result, referral to psychological service providers occurs primarily when parents of children with cancer are seriously worried, anxious or depressed. In the Democratic Republic of Congo, no psychological screening programs are in place to enable health care providers to identify parents at high risk of psychological morbidity so that clinical interventions can be initiated earlier and thus prevent serious cases. Psychological disorders occur during the course of the disease [5]. The therapeutic decision in children who have been fortunate enough to have an early diagnosis must be made quickly in agreement with parents. Cancer management remains a special experience for the child, his entourage and caregivers. After an initial study on the epidemiological and histological profile of childhood cancer in Lubumbashi, DR Congo [6] this survey attempts to assess the psychological barriers to the management of childhood cancer in our country.

\section{Material and Method}

The study area covers the city of Lubumbashi in the Democratic Republic of Congo. The study was conducted over two-year period, from January 2018 to March 2020 at the Clinics University of Lubumbashi, in the Department of Pediatrics in the Pediatric Oncology Unit. This study was based on a main role of psychosocial lived experience of parents with children affected by cancer, in additional to assess the costs of managing different childhood cancers. We have retained 129 children that parents or legal guardians had given a written document to admit their consentient. The study was focused on children under the age of 18 living with previously diagnosed cancer. Note that the pediatric oncology unit is a unit of the Department of Pediatrics which has internal organizations for the smooth running and follow-up of patients with cancer. These are the reference services for children with cancer with an oncopedaitre working 
closely with pathologists, radiologists and others. The latter has a structure for recording data relating to and monitoring each patient inpatient or outpatient follow-up for a cancer case. Hospitalization records, surgical and anatomopathological reports, patient records, death registry and diagnosis of each patient were recorded after diagnosis was confirmed in the database at the pediatric oncology unit of both departments. Based on a fact sheet the data was collected. Regarding the inclusion criteria, all parents of children seen in consultation for a clinically and/or radio logically confirmed cancer case, histologically and who agreed to respond to our questionnaire with informed consent, were included in our study. However, a questionnaire was sent separately to parents of sick children and to medical staff in the pediatric oncology unit. The investigators were trainee physicians and physicians specializing in general pediatrics of CUL. He had the questionnaire completed to the households during the pre-consultation wait. The questionnaire for physicians was made available at the pediatric level. This questionnaire included items related to the socio-demographic characteristics of children with cancer as well as the psychosocial aspects of households. The data was entered using Excel software and their analysis using SAS 9.4 software (Institute Inc., Cary, NC, USA). The characteristics of the group of children and their guardians were summarized by descriptive statistics especially with central trend measures and proportions. The Wilcoxon test was used to compare the median types of cancer in both sexes (male and female). The analyses were considered significant at the $\mathrm{p}<0.05$ serving threshold. The study was approved by the medical ethics committees of the University of Lubumbashi (UNILU/CEM/135/2018).

\section{Results}

One hundred twenty nine child's tumors were diagnosed during the period of our study, which we identified during one of the consultations for a confirmed cancer case, out of a total of 3024 pediatric visits to CUL, which corresponds to a hospital prevalence of $3.27 \%$ and an incidence of 47 new cases per year.

Male predominance was observed $(57.4 \%$ male versus $42.6 \%$ female) with a sex ratio of $(\mathrm{H} / \mathrm{F})$ of $1 / 4$. The average age was $5.47-3.41$ years ( 0 - 17 years). As many boys as girls were affected in the $0-9$ age group and 10 to 17 years. We noted that nearly $69.8 \%$ of children were between the age of 0 and 9 .

In (91.4\%) in cases, children's households had a low socio-economic level and fully cared for children (96.04\%). For all socio-demographic characteristics, there was no statistically significant difference between the two sexes. Most of children consulted with a confirmed cancer diagnosis were at an advanced stage often with metastasis (64.9\%). Of these, $54.4 \%$ were stigmatized and a significant number rejected the diagnosis outright at the announcement (11.7\%).The therapeutic protocol followed in our environment was chemotherapy (82.1\%) depending on the type of cancer following the GFAOP protocol adopted in our oncopediatric services. On the other hand, some others patients just benefit from surgery (5.8\%). Most of our patients were accompanied by one of the guardians 
(98.3\%) and in (58.8\%) they were female or the direct mother of the sick child. In several cases caregivers or guardians that accompanied sick children had a low schooling level (53.0\%) and their religious beliefs, majority were Christian (72.8\%). Childhood cancer was perceived by guardians as a serious and fatal disease $(73.9 \%)$ and in general, households had already heard of cancer $(88.3 \%)$ but did not think, in $(94.8 \%)$, that children could also suffer from it. Some households used healers and traditional practitioners $(42.1 \%)$. In our environment post-diagnosis counselling is almost non-existent $(82.1 \%)$ and after the diagnosis was announced, we found no sense of revolt and guilt among parents (Table 1). On the other hand, advertising conditions were found to be poor (71.2\%) characterized by reaction such as emotional shock that was the most common direct reaction in some tutors (67.7\%). On the socio-economic level of households, cancer has had an impact on the working life of households with absenteeism rates $(79.3 \%)$ and an increase in resource to rent to care at $(100 \%)$

Table 1. Parent characteristics $\left(\mathrm{n}^{\circ} 129\right)$.

\begin{tabular}{|c|c|c|}
\hline Parameters & Frequency & Percentage (\%) \\
\hline \multicolumn{3}{|l|}{ Lived at the announcement of the diagnosis } \\
\hline Emotional shock & 82 & 63.6 \\
\hline None acceptance during the Diagnosis & 31 & 24.0 \\
\hline Violent reaction & 16 & 12.4 \\
\hline \multicolumn{3}{|l|}{ Type of support that family has received } \\
\hline Psychological & 49 & 37.9 \\
\hline Social & 54 & 41.8 \\
\hline Financial & 26 & 20.3 \\
\hline \multicolumn{3}{|l|}{ Reaction with people around } \\
\hline Indifference & 81 & 62.7 \\
\hline Rejection & 35 & 27.2 \\
\hline Mockery & 8 & 6.2 \\
\hline Other & 5 & 3.9 \\
\hline \multicolumn{3}{|l|}{ Relationship with the medical profession } \\
\hline Acceptable & 76 & 58.9 \\
\hline Hard & 24 & 18.6 \\
\hline Good & 29 & 22.5 \\
\hline Schema therapy chirurgical & 19 & 14.7 \\
\hline Chemotherapy & 73 & 56.6 \\
\hline Radiotherapy & 8 & 6.2 \\
\hline Palliative care & 25 & 19.3 \\
\hline Other & 4 & 3.1 \\
\hline
\end{tabular}


in all households. There was also a lack of medical coverage in (57.5\%). House loan $(26.1 \%)$ households believed in their child's recovery after talking about the cancer diagnosis, but most (77.3\%) had accepted the treatments and the others because of lack of financial means the rest for lack of financial means could not. Sadness was the most common feeling after the onset of chemotherapy in some tutors $(69.5 \%)$. The entourage remained indifferent to the condition of a child living with cancer $(71.7 \%)$ and the child was rejected in (22.2\%) (Table 1). The relationship of households with medical personnel was considered acceptable in (66.7\%) (Table 1). The therapeutic path of households was long in the majority (83.9\%). The delay in care was also considered to be long in (78.1\%). Family suggestions for improving the care of their sick children were mostly related to material and financial assistance (95.6\%) and in only (8.1\%), alluded to a more appropriate space for the announcement of the diagnosis.

\section{Discussion}

Cancer is a disease that connotation is commonly associated with death. This perception may explain why attention is often focused on the patient, his suffering and his experience. The family is often put in the background. However, the illness raises many questions, it is often difficult to accept and represent a moment of crisis for the family. The onset of a serious illness in a person threatens and alters the balance of his or her family system [7].

Being diagnosed with cancer is ruff to accept for both patients and their loved ones, as it puts the patient to the test not only as a person, but also the entire emotional and social context from which he is born. Furthermore, during the period of our study we selected 99 guardians of children with confirmed cancer with a hospital prevalence of $2.4 \%$. Kamate et al., in 2014 had found a prevalence of $3.5 \%$ in Mali.

Assumptions about the increase in the incidence of childhood cancers in our country are to be elucidated by other studies. In Africa, the rate is $2.4 \%$ (137/5758) in Côte d'Ivoire; 5.8\% in Brazzaville [5]; 7.3\% (193/2647) in Guinea; 17.5\% (162/926) in The Gambia [6] [7]. For WHO [8], Sommelet et al. [9] noted the proportion of pediatric cancers at about $2 \%$ to $3 \%$. This difference could be sought either in sources of information or in etiological factors such as infectious and environmental. In our study, male gender predominated (57.4\%) with sex ratio of 1.4. This confirms the sex ratio figures observed elsewhere in Africa 1.7., Nigeria; 1.3, in Algeria and Brazzaville [10] [11]. Assumptions about the boy's improved access to care [19], the role of genetic [9] and environmental factors need to be explored [11], needless to say the level of parental awareness and the financial means for access to care that are quite expensive for households.

In our study, the average age reported in our study was (5.47 - 3.41 years). In sub-Saharan Africa, the average age was 6.7 - 4.3 years, which is slightly higher than the age found in our environment [12]. The age group most affected is 
under 9 years of age and accounts for $69.8 \%$ of cases, but the age-related case-to-population curve indicates a gradual increase with age. This is approximately a decade younger than patients in developed countries, and similar to developing countries. This could be favored by the late stage of discovery of the disease, which is consistent with Yao's work in the Ivory Coast and Traoré in Mali [13] [14].

Cancer management in our community has evolved considerably with the avenue of the pediatric oncology unit of the CUL and the development of research. In Europe and as in all developed countries, rapid treatment is increasingly being implemented with a cure rate of around $80 \%$ [15] [16] [17] due to early diagnosis of the disease. In our exercise context, a therapeutic protocol put in place by the Franco-African pediatric oncology group (GFAOP) remains a good compromise [4]. Unfortunately, diagnosis often at a late stage (64.9\%), lack of equipment and lack of a qualified hand frequently results in a large number of misbehavior on treatment which results in a stigmatization found in $54.4 \%$ of cases.

The level of education of the guardians accompanying children was in most cases secondary or low $50.3 \%$. This average level of schooling is found in other African studies, notably Traoré in Mali [18]. The level of education could have an impact on understanding and accepting the disease as well as on adherence to treatment. A low level of education, coupled with the lack of medical coverage, would contribute to more frequent use of traditional practitioners. However, the therapeutic pathway of families often reveals a high rate of ignorance among health workers, as childhood cancer is generally unknown by health professionals [4] [8] [19].

Would religion play a role in accepting care? We found that in $72.8 \%$ cases, households had their religious beliefs for Christianity. However, the role of religion as a refuge for cancer patients is not specific to a religious group. Several studies in the West reveal that religion alleviates the distress and despair of the sick and allows them to accept illness as the destiny God has reserved for them [20] [21]. Support through religion is generally beneficial for patients' quality of life, especially in overcoming anxiety and depression.

It should be noted that parents or caregivers had heard of cancer in $88.3 \%$ of cases, but $94.8 \%$ thought that children were spared, hence perhaps the lack of guilt observed in this survey. This same trend was found in a Yao [12] study conducted more than 13 years ago in Ivory Coast.

Announcing a serious illness such as cancer is never an easy situation for both patient and doctor. For this reason, cancer announcement system has been set up as part of the Cancer Plan in France [22]. This scheme has improved the conditions for reporting cancers in France in particular and also in developed countries in general [14] [15]. In Africa, GFAOP has made a significant contribution to improving the management of childhood cancers and has recently implemented an announcement guide [16]. However, our survey shows that in more 
than half of the cases, parents reported that the advertising conditions were not appropriate. These announcement conditions aggravate the distress of the families [23]. The announcement of the cancer diagnosis, nowadays, must follow very specific rules. It requires an ability to understand the information given (literacy but also the use of local languages or images), the patient's involvement as an actor in his health, a desire of the patient to be better informed, his involvement in the choice regarding medical decisions and possible treatment options.

Cancer has a significant impact on the quality of life of households. In fact, the average expenditure during this condition was USD (1932-322) or nine times the minimum income (Smig) and $95.7 \%$ of households had no health coverage.

In our case, 23 parents of the patients had refused the therapeutic protocol for lack of financial means. The lack of social security, the high cost of treatment, the irregular availability of anti-cancer drugs, the lack of specialized hospital infrastructure, contribute to the deterioration of the quality of life of our patients. In this context of difficult care, households had received very little psychological support (42.5\%) from the relatives. Lack of financial resources, on the one hand, the non-adherence of parents to care, on the other, are the main causes of the long delay in the care of children and a large number of lost sight.

The vast majority of attendants felt that they had an acceptable relationship with medical staff in $77.2 \%$ of cases. Our results are similar to those of Grenier et al. with 77\% satisfaction rate of the doctor-sick relationship [24] [25].

The child's illness was frequently responsible for absenteeism of co-workers at work in $79.3 \%$ of cases; often a source of professional conflict, resulting in increased family suffering.

\section{Conclusion}

Psychosocial lived experience of parents with children diagnosed with cancer in the DR Congo mostly in Lubumbashi has to be improved in multiple ways. The study has showed that majority of parents have low level of knowledge in childhood cancer even if they have heard about it before, besides the costs of healthcare still a big issue for caregivers or parents with children diagnosed with cancer, moreover the lack of materials, specialists as in developed countries don't allow to go under the process as in developed countries and there is no assistant for parents neither guardians. According to researchers opinion or our time we think parents need some emotional support and children could benefit some financial help in order to get the treatments and help they need. All in all many African countries still have the same issues which impact the way of giving health care to patients and provided emotional supports and enhancing parents knowledge in childhood cancer.

\section{Contributors}

Study design: Criss KOBA MJUMBE, Benjamin KABYLA ILUNGA, Béatrice KOBA BORA, and Prosper KALENGA MWENZE; 
Data collection: Criss KOBA MJUMBE and Henri MUNDOGO TSHAMBA;

Data analysis: Criss KOBA MJUMBE, Oscar LUBOYA NUMBI MD and Jean Pierre BIRANGUI;

Drafting of the manuscript: all authors.

\section{Acknowledgments}

The authors thank their study coordinators (Benjamin KABYLA ILUNGA, HENRI MUNDONGO TSHAMBA, Prosper KALENGA MWENZE and Oscar LUBOYA NUMBI), the staff of the Department of Pediatrics and Public Health of university clinics in Lubumbashi, particularly of the pediatric oncology unit. As well as the intern doctors, nurses and doctors who helped us approach households on our behalf. Dr. Criss KOBA MJUMBE would like to thank his thesis director and the members of his supervisory committee. Finally, this study would not be possible without the generous participation of households of children with cancer.

\section{Conflicts of Interest}

The authors declare no conflicts of interest regarding the publication of this paper.

\section{References}

[1] Zografos, L. (2002) Rétinoblastome. In: Tumeursintraoculaires. SFO \& Masson, Paris, 463-619.

[2] Berete, C., Ouffoue, G., Kouakou, K.S., et al. (2014) Évaluation du rétinoblastomeau CHUdeTreichvillede1995à2012: étuderétrospective de 115 cas. AfrBiomed, 19, 12 20 .

[3] Taleghani, F., Fathizadeh, N. and Naseri, N. (2012) The Lived Experiences of Parents of Children Diagnosed with Cancer in Iran. European Journal of Cancer Care, 21, 340-348. https://doi.org/10.1111/j.1365-2354.2011.01307.x

[4] Wong, M.Y.-F. and Chan, S.W.-C. (2006) The Qualitative Experience of Chinese Parents with Children Diagnosed of Cancer. Journal of Clinical Nursing, 15, 710-717. https://doi.org/10.1111/j.1365-2702.2006.01297.x

[5] Isango, I., Criss, K.M., Kabamba, N.M., et al. (2020) Hypertensive Pathologies in Peripartum: Complications and Maternal and Neonatal Outcome. Open Journal of Obstetrics and Gynecology, 10, 311-318. https://doi.org/10.4236/ojog.2020.1020027

[6] Janice, M. and Lorraine, M. (2015) Watson the Illness Beliefs Model: Advancing Practice Knowledge about Illness Beliefs, Family Healing, and Family Interventions.

[7] Criss, K., Kabyla, I., Kalenga, M. and Chisuili, Y. (2020) Epidemiological Profile of Childhood Cancers in Lubumbashi. Africa Scientific Journal.

[8] Institute of Medicine (US) (2008) Cancer Care for the Whole Patient. In: Adler, N.E. and Page, A.E.K., Eds., Meeting Psychosocial Health Needs. National Academies Press, Washington DC.

[9] Young, B., Dixon-Woods, M., Findlay, M. and Heney, D. (2002) Parenting in Crisis: Conceptualising Mothers of Children with Cancer. Social Science and Medicine, 55, 1835-1847. https://doi.org/10.1016/S0277-9536(01)00318-5

[10] Ward, E., De Santis, C., Robbins, A., et al. (2014) Childhood and Adolescent Cancer 
Statistics. CA: A Cancer Journal for Clinicians, 64, 83-103. https://doi.org/10.3322/caac.21219

[11] Dickerson, S.S., Boehmke, M., Ogle, C. and Brown, J.K. (2006) Seeking and Managing Hope: Patients' Experiences Using the Internet for Cancer Care. Oncology Nursing Forum, 33, E8-E17. https://doi.org/10.1188/06.ONF.E8-E17

[12] Jehanne, M., Brisse, H., Gauthier-Villars, M., Lumbroso le Rouic, L., Freneaux, P. and Aerts, I. (2014) Le rétinoblastome: Les avancées récentes. Bulletin du Cancer, 101, 380-387. https://doi.org/10.1684/bdc.2014.1931

[13] Dockerty, J.D., Skegg, D.C. and Williams, S.M. (2003) Economic Effects of Childhood Cancer on Families. Journal of Paediatrics and Child Health, 39, 254-258. https://doi.org/10.1046/j.1440-1754.2003.00138.x

[14] Berete, C., Ouffoue, G., Kouakou, K.S., et al. (2014) Évaluation du rétinoblastome au Centre Hospitalo-Universitaire de Treichville de 1995 à 2012: étude rétrospective de 115 cas. African Journal of Biomedical Research, 19, 12-20.

[15] Bey, P. (2013) Le cancer en Afrique. Bulletin du Cancer, 10, 112. https://doi.org/10.1684/bdc.2013.1692

[16] Lemerle, J. (2003) Traiter les cancers des enfants en Afrique. Archives de Pédiatrie, $10,245 \mathrm{~s}-252 \mathrm{~s}$.

[17] Yao, A., Attimere, Y.N., Oulai, S.M., et al. (2008) Vécu psychologique des parents accompagnateurs d'enfants hospitalisés en oncologie pédiatrique. Carcinol Prat Afrique, 8, 61-66.

[18] Koba, C., Isabelle, K.O., Benjamin, K.I. and Oscar, L.N. (2020) Problem of the Management of Haemorrhagic Fevers: Experience of Ebola Virus Disease in the Province of North Kivu and Ituri (DR Congo) and the Importance of Early Diagnosis. Open Access Library Journal, 7, e6135. https://doi.org/10.4236/oalib.1106135

[19] Programme national de cancer (2018) Recommandations nationales pour la mise en œuvre du dispositif d'annonce du cancer dans les établissements de santé. Mesure $40 \mathrm{du}$ Plan cancer RDC.

[20] Fotiadou, M., Barlow, J.H., Powell, L.A. and Langton, H. (2008) Optimism and Psychological Well-Being among Parents of Children with Cancer: An Exploratory Study. Psycho-Oncology, 17, 401-409. https://doi.org/10.1002/pon.1257

[21] Gall, T.L. (2004) The Role of Religious Coping in Adjustment to Prostate Cancer. Cancer Nursing, 27, 454-461. https://doi.org/10.1097/00002820-200411000-00005

[22] Koba, C., Bakari, A., Laura, T.Z. and Béatrice, K.B. (2020) Knowledge, Attitude and Practice of Traditional Healers on Epilepsy in Lubumbashi. Open Access Library Journal, 7, e6446. https://doi.org/10.4236/oalib.1106446

[23] Diekelmann, N. and Ironside, P. (1998) Hermeneutics. In: Fitzpatrick, J., Ed., Encyclopedia of Nursing Research, Springer, New York, 243-245.

[24] Lolonga, D., Pondy, A., Guédénon, K.M., Gbadoe, A., Barsaoui, S., Bouda, C.G., et al. (2015) L'annonce du diagnostic dans les unités d'oncologie pédiatrique africaines. Revue d Oncologie Hématologie Pédiatrique, 3, 29-36. https://doi.org/10.1016/j.oncohp.2014.12.001

[25] Yah, C.H. (2002) Life Experience of Taiwanese Adolescents with Cancer. Scandinavian Journal of Caring Sciences, 16, 232-239. https://doi.org/10.1046/j.1471-6712.2002.00066.x 